\title{
Bildung, Meditation and Safe Haven
}

\author{
Janine Joyce \\ National Centre for Peace and Conflict Studies, University of Otago, New Zealand
}

\begin{abstract}
Many philosophers globally - ranging from Aristotle, through to the eastern Vivekânanda andEuropeans,Immanuel Kant, Emmanuel Levinas and Wilhelm von Humbolt- espouse the possibility andcapability of humanity to evolve into a higher level of relationships with each other and consequently of consciousness. Akey requirement for this to occur is the individual's transformation of mind, body and heart.

This paper argues that Universities are ideally situated to facilitate the spiritual practices, attitudes and openness that can allow an individual to develop the capacity to welcome such a journey ofself-transformation. It is the capacity to allow, nourish and provide safe haven for individuals to develop a harmonization of mind, body and heart which many believe leads to the natural expression of noble ethics and the virtues required for them to be articulated. This process is one that by nature occurs deep within the individual being both spiritual and transformative. Spiritual processes such as meditation are posed as practical in facilitating some aspects of a classical spiritual definition of Bildung (or education).

Specific examples of lived individual transformation are included from a purposive sample of Sahaj Marg Raja Yogal meditation practitioners interviewed using a semi structured open-ended question style, which included the question- what is Spiritual Brother-sisterhood? Those interviewed had all been nominated and had attended a four week residential International Scholarship Training Program(ISTP ${ }^{2}$ ) with twenty-eight other Sahaj Marg practitioners from all around the world.
\end{abstract}

Keywords: Sahaj Marg; Spiritual brother-sisterhood; Meditation;Bildung; Transformational ethics; Contemplative education; Contemplative pedagogy; Raja Yoga; and Safe Haven.

\section{Bildung}

Originally the concept of bildung referred to a person's face (Nordenbo, 2002) but by the 1750'swas being used as a concept in the educational thinking of the enlightenment whereby the "nature ofbildung was the harmonious development of spiritual powers and its realization through imitation ofthe classical Greek model".

In this spiritual way of understanding bildung the individual was provided with the means tocultivate his/her according to his/her own view. This definition of bildung rests upon theharmonious development of spiritual powers. Whilst it is not clear what the harmoniousdevelopment of spiritual powers might mean within bildung it is possible that practices that bynature are spiritual may contribute to its expression and with the realization of human beings whoare cognizant and open to expressing mind, body and soul as an integrated whole.

Joseph Bleicher (2006) in his summary definition identifies qualities and characteristics of manifestbildung as:"God, nature, community: these thus are the points of reference for bildung. Transcending mere acquisition of knowledge, bildung points to a way of integrating knowledge and expertise with moral and aesthetic concerns. On the basis of successful integration of thinking, willing and feeling, it enables sound judgment, indicated by a developed awareness of what is appropriate, and is expressed by tact, good taste, and a sense of community. It entails openness to difference and willingness to selfcorrect. Bildung in the classic sense, thus also contains a projective anticipation of the "good life", of human freedom enacted with responsibility for self and others in the open-ended project of self-creation" (Bleicher, 2006: 365).

This could be seen as in conflict with the needs of a community or a state however, and the idea of the Greeks and also other writers on bildung suggest that it is only in service to the community, in self-restraint and submission to ethical demands, can bildung shape the individual. So this is a secular conception to suggest that what shapes the individual from beyond itself can only be the state or a community. Spirituality alludes to the capacity for an inner existential reality capable of encouragingtransformation (Chui et al, 2004).

It appears that classical bildung is not merely education in a sense of imparting factual knowledge but a way of shaping the integration of the one being educated so that the knowledgegiven transforms and improves

\footnotetext{
${ }^{1}$ https://www.sahajmarg.org/seeker/practice

${ }^{2}$ An International Scholarship Training programme for Sahaj Marg raja yoga. A one month residential training programme for practitioners from all countries
} 
or completes towards an ideal. A combination of spiritual development that leads to character and ethical development, including discernment and an ability to relate to others (Varkoy, 2010; Wimmer, 2003).

In many ways the concept of bildung represents a paradigm shift within education away from marketbased priorities focused on self-satisfaction and entitlement, towards a paradigm concerned with the development of personal human virtues, perfection and spirituality (Prange, 2004). According to Roland Reichenbach:

"Bildung is not only a productive and reflective appropriation of world to one's self but—and this is a special case of productive-reflective appropriation-Bildung may also include afirm rejection of world, even if such an act may appear quite narrow-minded under specific societal and cultural conditions" (Reichenbach, 2003: 206).

For this radicalisation to be manifest it is likely that the developing mind of an individual will need aplace of safety or haven such that the expression of ideas that may not conform to the mainstreamare welcomed. For this to occur there must also be a welcoming and allowing of reflective andcontemplative opportunities built intothe culture of the University orits courses (Prange,2004). The use of spiritual techniques, particularly those associated with inner decentralisation or renunciation to educate the mind and create an attitude, whereby onedwellsin a space of contemplation and reflection, allows processes that seem similar to bildung. Yogic philosophy postulates that:

"All the actions that we see in the world, all the movements in human society, all the worksthat we have around us, are simply the display of thought, the manifestation of the will ofman. This will is made by character, and character is manufactured by Karma" (Vivekânanda, 1899: 18).

From a Raja yogic perspective of transformational development, the endeavor to reach Divine realization (transformation of mind and matter) occurs as a consequence of meditation practice that lifts one out of the cycle of karma or zero-sum action and reaction (Vivekânanda, 1899).

\section{Meditation}

Meditation has been defined as a devotional exercise of or leading to contemplation, as a contemplative discourse, usually on a religious or philosophical subject. ${ }^{3}$ Meditation has been additionally defined as the continuous and profound contemplation or musing on a subject or series of subjects of a deep nature; "the habit of meditation is the basis for all real knowledge,"4 reflection, thought, concentration, study, musing, pondering, contemplation, reverie, ruminating, rumination, and cogitation. ${ }^{5}$ Within the work of Aristotle we see links between meditation and 'bios theoretikos', whichdescribed the thinking life as a life whereby action became balanced by contemplative thoughtin light of the argument and correction of one's own self-interested view of life (Backman, 2006).

The philosophy of Yoga, as collated by Patanjali in the second century B.C.E. describes a range of physical, mental and psychic processes that were aimed at bringing together spirit and matter. Hiswork gives some interesting insight into the states of the thinking mind (Prasada, 1912). Patanjali accepted theSankhya school of Indian philosophy and identified the main cognitive mental states (citta) ofhuman beings as: a) cognition, b) false cognition, c) merely verbal cognition, d) sleep, and e) memory (Prasada, 1912). Alongside these cognitive mental states there were also identified five conditions ofmental life: a) restless, b) torpid, c) distracted, d) concentrated and e) restrained. Whilst theafflictions of self included: a) wrong knowledge, b) false notion, c) desire, d) aversion, and e) aninstinctive fear of death. The true self was viewed as a shining intelligence, which emerged whenthe self was no longer, identified as any of the states, conditions or afflictions of citta. The true self was said to be a stable inner conditionof calm, stillness and coherance in which the reality and order of things is clear and one's place in that order is known. This seemssimilar to the concept of bildung whereby the true purpose of a human being was to bring allstrengths into one integrated whole situated amongst one's fellows. From a Yogic perspective whilst the self was identified withcitta then the focus of attention remained on the body and yoga or 'union' was not achieved. Theconcept of 'citta' has some implications for any pedagogy encouraging bildung. An educationalenvironment encouraging a competitive, skills-based procuring of personal advantage in the market environment may domuch to promote the types of mental states said to preclude the union of mind and matter. Perhapsthese states inherently interfere with the capacity of an individual to manifest the harmonization ofclassical bildung. It seems likely that the potential afflictions of citta interfere with individualscapacities to be truly present with each other and capable of entering into discourse that is open andflexible and not directly or indirectly focused on personal interests and desires.

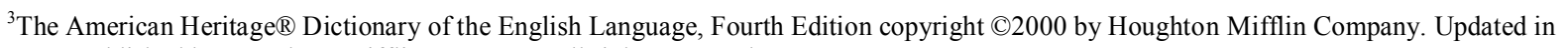
2009. Published by Houghton Mifflin Company. All rights reserved.

${ }^{4}$ Based on WordNet 3.0, Farlex clipart collection. @ ( 2003-2011 Princeton University, Farlex Inc.

${ }^{5}$ Collins Thesaurus of the English Language - Complete and Unabridged 2nd Edition. 2002 @ HarperCollins Publishers 1995, 2002
} 


\section{Safe Haven}

Pearmain's (2007) study identified the theme of 'safe haven' in a comparative study of youth attending Quaker and Sahaj Marg camps and seminars. This applied research finding was useful when considering the potential role of universities in the capacity to provide environments conducive to a certain flowering of consciousness. According to the Oxford dictionary 'haven' means any place of shelter, safety, refuge and/or asylum. It has also been defined as a harbor, port, as a place of safety, as a refuge and as a place offering favorable opportunities or conditions for example: a haven for artists. Other words used to define haven include sanctuary, shelter, retreat, asylum, refuge, oasis, sanctum, a harbor; a place of safety and/ or rest. A classical definition of bildung rests upon a notion of pedagogy, which is both spiritual and separate from the religious. It is the value base, practices, wisdom and scholarship of spirituality that requires safe haven from the forces of market driven economies and material consumerism. In modern technological societies the first place of haven for concepts relevant to bildung mayoccur within legislation whereby ideas conducive to bildung are mandated. As an example AotearoaNew Zealand's 1989 Education Act defined Universities as having a number of characteristicsincluding: that they accept a role as critic and conscience of society. It is recognized that the University acts as both critic and conscience of society givingpermission for the exploration of ideas, which may not confirm the dominant paradigm of globalcapitalism. Whether this occurs in actual practice requires further research but what remains is that it is mandated within the legal underpinnings.

\section{Haven For The Spiritual And Transformative}

According to Breznitz and Feldman, (2010) modern universities have four key roles including:workforce development, partnership development, community development and real estatedevelopment. These roles are based upon a philosophical attachment to market materialism. Somescholars have differentiated between views that see higher education as a public good whilst otherstake a more market driven view whereby universities are primarily concerned with economicsurvival at institutional and nation levels (Datur, 2005). In this it seems difficult to argue thatuniversities are ideally located to protect the ideals of classical bildung. Some commentatorshowever are beginning to question whether these values are sustainable and whether universitieswill be seen to be less relevant particularly if jobs are not forthcoming after significant privateinvestment (Ford, 2002).

Universities potentially conceptualized as safe havens allow the capacity for connection and free expression of ideas conducive ultimately to growth in creativity; some of which require physical safe haven from that permitted politically so that they provide philosophical safe haven from the economic colonization of ideas and a pervasive materiality focused on self-satisfaction.

Around the world there are examples of universities being established to provide haven to ideas that can be understood as spiritual. The United Nations University for Peace in Costa Rica is one such initiative. The University was set up with its own charter in order to protect academic freedom and has as its stated mission:

"To contribute to the great universal task of educating for peace by engaging in teaching, research, post-graduate training and dissemination of knowledge fundamental to the full development of the human person and societies through the interdisciplinary study of all matters related to peace.."

The notion of bildung asks us to consider how we prepare the workforce for a world whose current market driveninitiatives appear unsustainable. What values and pedagogical styles should universities offer? Alongside this is the wondering; Are students open to a spiritual pedagogy? A recent qualitative study by Rosalind Pearmain of young peoples' experiences at summer camps for the Quakers and at a Sahaj Marg Raja yoga camp (Pearmain, 2005) ${ }^{7}$ identified two key themes, which were valued by the young people. These were safe haven andtransformational experience. What was powerful in their narratives was the way in which theyappreciated haven from the forces of materialism and pretence, where they could be themselves andbe open

\footnotetext{
hittp://www.upeace.org/

"To ensure academic freedom, the University was established under its own Charter, approved by the General Assembly. UPEACE is not subject to UN regulations and is directed by its own Council of renowned personalities with expertise in peace and security matters. This has allowed the University to move rapidly and to innovate, focusing its new, rigorous academic program on the fundamental causes of conflict through a multidisciplinary, multicultural-oriented approach. The wider mission of the University should be seen in the context of the worldwide peace and security objectives of the United Nations. The central importance of education, training and research in all their aspects to build the foundations of peace and progress and to reduce the prejudice and hatred on which violence, conflict and terrorism are based is increasingly recognized".

${ }^{7}$ This qualitative study with a group of 12,15-18-year-olds during a summer school week known as Senior Conference run by the Quakers for about 80 participants. The group had eight 18-year-olds, three 15-year-olds and one 17-year-old in the group of five males and seven females. A comparison group of, six 15-18-year-olds in Denmark were interviewed. They were participating in a young people's seminar of 40 participants within a wider age range from 16-25, held at a center for Raja Yoga meditation system (Sahaj Marg). In this group, four were female and two were male; two were 15 , two were 17 and two were 18 .
} 
with others. They spoke of transformational silences and the capacity to feel safe. Theywere also practical in the way that they saw this openness as being able to be expressed in theirhome communities. As Rosalind Pearmain writes the camps offered the youth:

“...opportunity for participants to be safe to become themselves, to be increasingly open to others and themselves, and to explore many avenues of learning and discovery. Intenseemotional reactions might be generated in all of this and fundamentally they felt supportedby the holding of a spiritual space in which they could be silent, reflect, feel connected andallow deeper insights to surface. From this perspective, the narratives are intertwined withthe difficulties of growing up and managing belonging and separateness, finding deeperinspiration and meaning as a vehicle to support their life direction and quite simply increasing confidence in themselves and the world".

This study provides useful insights when considering what an educational approach sensitive to theideals of bildung might offer young people:

"The safe haven could be seen as grounding support for the immense anxieties and self-doubt that young people face in the context of intense commercial pressures to look rightand to own the right possessions and to confront significant cynicism and denigration ofspiritual and human values".

So protecting the value of bildung within education institutions potentially offers our youth theopportunity to experience a way of being, which is novel, and currently under siege in moderntechnologically advanced societies. What was heartening from the above study, albeit with a smallsample, was the way in which the youth appreciated the opportunity to allow transformativeexperience into their lives. ${ }^{8}$

Aristotle lends support to the idea that this is an important role for Universities when he argues that the correct time for becoming 'good' is whilst one is a youth and through the process of right training (Barker, 1946). He continues by asking how such training should occur and within what institution should such training be offered. He takes the view that the state and the law should take a key role in this:

"Through a system of law, and in the state'. In order that it may turn from knowledge to act, ethics thus becomes a matter of legislation, and thereby a concern of politics" (Barker, 1946: 356).

For Aristotle the process of growing as a human being includes, energy, purpose, form and power tohis or her soul. For the soul to be effective in the world or develop real powers, it must not onlyreceive theoretical knowledge that reveals aspects of the world for intellectual contemplation andfruitful speculation but also practical knowledge that reveals not only how one does things, but also what ought to be done (Miller, 1999).The 'ought' here is objective in the sense of equal concern with the well-being of all rather than focused or restricted to the advantage of the individual.

Mere political training as we understand it, may not facilitate theideas uponwhich classical bildung rests. In many waysbildung interpreted more widely, asAristotle would, rather than in accordance with a narrow reading of his political philosophy, runscounter to the current economic and intellectual colonization that is occurring within Westernizedmarket economies and the institution they create. Aristotle again argues that for an individual to become good they must first be habituated and trained properly, and then goon to spend time in the 'spirit thus engendered, on worthy occupations- doing nothing base or meaneither willingly or unwillingly.' Already we see difficulties. How do we engender a lifelong lastingspirit of openness and willingness for students who graduate and may very well find employment inbase, mean and self-serving, uncertain and undervaluing industries?

Can Universities as institutions be reasonably expectedto provide safe havenfor such ideals? Certain values seem more obviously suitable: truthfulness, fairness, tolerance, responsibility. Butwhat about the others? Do systems anchored to passing and failing students demonstrate tolerancefor difference of understandings, paradigmperspectives andthe like? What does anotion ofbildung requests of us? Can we offer safe haven to notions of the spiritual implicit in classicalbildung and under attack from the dominant paradigm of economic materialism? (Coholic, 2006) Ata pragmatic level, scholarship suggests that such binaries of thinking are not useful. Ho (2011)studied the effect of meditation on employees' self -directed learning in fifteen technologicalcompanies in Taiwan. The findings demonstrated that meditation significantly and positivelyinfluenced employees' self-directed learning readiness, alongside measurable improvements incompanies' organisational initiative capability and organisational performance (Ho, 2011). In thisexample we find that skills based upon spirituality enhance the capability of the workforce. It maynot need to be conceptualised as a binary either/or argument.

Contemplative education practices have as their goal the enhancement of skills and ways of being inthe world such as mindfulness, awareness, empathy, and authenticity, encouraging a deepintelligent union of intuition and intellect. There has been a view that practices based uponspirituality represent the realm of the

${ }^{8}$ One other study incorporating mindfulness meditation training into a university course in the USA and in Austria reported that's students were very positive about their experiences although the paper noted that contemplative education continued to be unusual in American higher education settings (Holland, 2006). 
religious and the individual separated from political effect. Research on meditation suggests the opposite. It seems that meditation creates change not only inthe heart of the practitioner but also the brain (Mograbi, 2011; Wang et al, 2011). Meditation practitioners appear to become more empathetic and relational and there is a flowering of a natural compassionate lived ethics (Rockfeller, 2006). Such a lived ethics has the potential to express itself in all realms including the political.

\section{Conductive University Policy}

At a pragmatic level a recent example from Manhattan College, in the USA demonstrates an infusion model of ethics teaching, which seems very compatible with notions of bildung. In this example ethics is infused into all sorts of religious studies programs which in turn provide liberal arts credits that are compulsory for all students including those outside of humanities for example; engineers. Specifically, the article describes the model as providing an opportunity for reflection upon the foundational ethical positions of the world's religions, thereby providing students a position from which 'they could not only ask what professional ethical code applied in a given situation, but also ponder the nature of character needed to follow such an ethical code' (Kaplan, 2006). This appears to be a practical way to encourage a concept of classical bildung within the modern educational environment. However, those from the Frankfurt school critical pedagogy, argue that imposing a conception of the good on another is always dominating and in direct opposition to those values that one is trying to offer. It is difficult to counteract that argument other than to acknowledge that spirituality tends to lead to the type of flexibility of thinking and behaving that contributes to anontology that things can be many ways, that there are many truths and that there can be a natural harmony in diversity. Thus imposing a conception of the good assigns a pre-formed conception whereas working towards one, an essential part of which is interpersonal harmony, has a quite different basis.

\section{Conductive Teaching Practices}

In the offering of safe haven Universities and their teaching staff may need to modelways of learning that encourage meditative practices, fraternal ways of communication and the development of teaching styles that encourage and do not penalize creative thinking.Currently within academic scholarship it appears that some Universities have begun to developcourses such that students have the possibility of learning more about such spiritual practices andthe traditions from which they spring. As an example Columbia University Teachers College, published an article on a course offered on 'Contemplative practices: educating for peace andtolerance' (Hill, Herndon \&Karpinska, 2006). They described a teaching process that allowed students to become more comfortablewith silence as a contemplative activity and described how students became better able to waitlonger before speaking. Educators were described as having the chance to encourage a respect forthe 'contemplative quest at the heart of diverse spiritual traditions' as separate to religion, with its associations associated with conflict. Students were encouraged to immerse themselves in a diverse range of wisdom traditions as well as scientific information on the effects of spiritual practice on the body and mind. Benefits from contemplative practices within the education setting including meditation are not only confined to students. A recent controlled studyexamined the effects of ordinary meditation on stress, anxiety and symptoms of burnout for a group of ninety-one teachers. The active group practised a five-week program of twice daily meditation (20 minutes duration). The results supported the hypotheses that standardized meditation significantly reducea teachers' perception of stress, lowered their state and trait anxiety levels, and decreased their experience of burnout, and were consistent with findings of other studies that have investigated meditation's effecton stress. What was also of interest was that whilst teachers almost immediately reported feelingless exhausted, their attitude and experience of depersonalization of students took longer to change. It was also interesting that changes occurred whether meditation was regular or less frequent thantwice daily with teachers being able to integrate some meditation into their busy schedules (Anderson etal, 1999).

\section{Examples from Raja Yoga lived practice}

Applied research from Raja yoga practitioners on Meditation and Spiritual fraternity is used to illustrate the concept of bildung/self-cultivation and the practical possibilities for transforming within such a hostile world in which one is taught to be self-regarding, self interested or focused on a possessive consumptive survival orientation.

We begin with one practitioner describing her experiences of learning to integrate and harmonizeduring a training seminar:

"Yes- like two days back we were sitting with people from different countries with differentbackgrounds but we were standing discovering/ researching (by the way we are all searchingin the same place) in our hearts and in the moment when we were adjusting ourselves fromthe mind to the heart we were all very attentive, caring we were listening to each other byheart in the moment. Before that we were somehow jumping back to the mind with our interrupting each other, not listening and not a very nice feel and right away 
after small adjustments and a few moments meditation we made the change". (Ukraine female Sahaj Marg practitioner)

In this example the practitioner describes a process of harmonization within the group setting where the group begins from an awareness that is self-focused and somehow gets in the way, towards an orientation involving awareness of connection, silence, meditation, and internal adjustment of both attitude and feeling or vibration. This appears to be a very practical way of demonstrating the integration and mastery of self that bildung aims to create. The internal adjustment took only 'small adjustments and a few moments' and then each was able to be with the other in a more respectful and mindful manner. She shows a process whereby individuals in a group who had no prior relationship or knowledge of each other (a training program with practitioners from Singapore, Ukraine, New Zealand and India) came together and developed skills in learning to care and listen intently from the heart. Central to the success of this was an established spiritual practice, which allowed the alert mindfulness, and self-control to allow correction of mind and behaviour. This allowed a movement from mind/self-focused thought, which placed everything in categories and highlights divisions and distinction to a mode of experience that was shared and connected.

Facilitators were required to model a deep calm silence with no use of probing questions, paraphrasing or similar skills. A task or question was given and group members listened and crafted a way of communicating from a platform of silence. Whilst this was novel participants commented on the way that they enjoyed learning from a platform of silence and reflection. Some researchers argue that incorporating meditation practices into higher education will contribute a number of benefits in the areas of student creativity such that: qualities such as inner calm, well-being, compassion, unboundedness, and freedom from anxiety that are accessed in meditation begin to gradually become present in everyday life (Sedlmeier et al, 2012; Ho, 2011; Ai, 2002).

It is possible that these capacities lead to human beings with a refined reflective capacity implicit toany infinite outpouring of bildung.

It is in the relationship between meditation and its fruits of connectedness and spiritual fraternitythat we begin to see possibilities of lived bildung. Imagine practices within Universities that would encourage such a relating with everyone coming from the heart and learning to listen. Such practices allude to a time when humanity taught through induction, story and silence; which allowed contemplation and absorption of the material. The experiences of oneness spoken of by experienced mediators would suggest that an environment where many individuals are together having had a similar exposure to spiritual ways of relating may allow a greater expression of bildung to emerge:

"Yeah when you first asked the question- I was just wondering about that question what does spiritual brotherhood mean? And when I entered this place I got a thought that it's a kind of awareness that we all are or have come from the same source. And just like when we are in a family- we have the brotherhood, we have the relations and we have the loved ones. So in a higher level or in a broader sense when we all came from the same source and if you get that awareness then that brings up the brotherhood with all life- that's what I thought. "(Indian male Sahaj Marg practitioner).

This practitioner alludes to the atmosphere as being conducive to a thought or a feeling of connection and common beginnings. So the atmosphere or environment of classrooms and participants may require mindful attention.

"I want to bring Master into all situations and I make that choice and I can see that it has already changed things for me. Like I'm a single mother and have a daughter who is twelve and sometimes we go into arguments and I'm more and more fast to remember to bring lightinto our situation and the minute I remember to bring Master or light into the situation I startsaying how can I do it and it changes the atmosphere like that so I find that our arguments ifwe have any or disagreements or whatever they become shorter and shorter and alwayswhen I decide to bring the light and remember that it changes and what changes is that Istep out of knowing what's right! And in the second I do it she can feel that she gets somespace and some space to explore what's really in her heart and lately she has said to me howcome you have never did this before?" (Danish female Sahaj Marg practitioner)

The master is here a personal principle of overarching being-as-one or family-hood and mastery ofthe disciplines of the true original essence of human self-hood or being. We can notice that she has lost the feeling that she is right and that her beliefs are to be imposed on others. These ideas are similar to thescholarship in conflicttransformation. Applied Researchwith Sahaj Marg Raja Yoga adultpractitioners reinforces the idea that the development of morality requires connection with the other,openness with the other and willingness to selfcorrect (author, unpublished $\mathrm{PhD}$ ). It seems that notions of classical bildung and yogic practice involve the shared goal of evolution ofeach human being towards values of goodness, which then perhaps are reflected in relationship andcommunity.

Another practitioner in response to the question what is spiritual brotherhood shared a process ofintegrated self-mastery whereby there was a willingness to be connected to others: 
"Being one with each and everybody and everything. Just listening to each person's heartand where they are coming from. It can be different feelings, it can be sad, it can be happy-you just have to go with the moment. I think it can be whatever it needs to be and that'sacceptable. Whatever it needs to be. You connect with the living Master, the Master within,that supports you and loves you and it is just at one with everything. I think it makes me feelconfident in myself, as I am not on my own whatever I need to do in life I can do. Becausel'm not on my own. The master? Well it certainly is energy positive and negative. It's morelike you get energy from different people around you and it could be negative or positivebecause it's like a living Master this energy. Everything's vibration. Just listen to what yourheart says and if its right just go for it and don't let doubt even appear in any shape or form, believe in yourself, believe in others and let them know that you believe in them".(Australian female Sahaj Marg practitioner)

So brother-sisterhood arising from a shared spiritual practice has a relational aspect whereby there is anincrease of basic willingness or awareness of core values such as tolerance and capacity toappreciate difference by raising our thought attention to the higher level of connections whereby weare energy and one. The master within encourages connectedness. This spiritual perspective gives this practitioner a sense of selfconfidence tolisten to her heart but also the confidence to listen and trust the heart of the other.

Another practitioner shares their experience of a group program with meditative and contemplativepractices embedded in the program:

"Every time when we sat during the International Scholarship Training Program prior to adiscussion when we would close our eyes and we would connect in with each other- it's likebeing more of a family then you can ever imagine and every time I think about you knowour togetherness it feels like what do you call it its like you've got the sun, you've got themoon, and that represents like Master and he's somehow looking at ... he's dispersedeverybody and we are so much connected we are so much connected with each other thatwe don't even know". (South African male Sahaj Marg practitioner)

In this example it is possible to imagine that such a process could led to the spirited and open discourse that classical bildung would welcome (Prange, 2004). Another practitioner shares the frustration during a meeting of returning to a communication style that was less open and connected:

"I was feeling like our hearts were connected because Iwas remembering the International Scholarship Training Program (ISTP) training and even the youth seminar we had where we had these kinds of sessions and we connected with our hearts for like a minute and then we started our chat. So it brought back a lot of memories from the ISTP training so I didexactly the same thing in the meeting you know and somehow it became spontaneous againand although I never wanted to say because sometimes people can get can hear the agitationin my voice... but I become agitated you know because they are somehow thinking toomuch with their intellect and not with their heart." (South African male Sahaj Marg practitioner)

This practitioner remembers a process whereby all small group activities began with a moment'ssilence to connect with an internal attitude of calm, respect and willingness alongside a connectionwith each person. He describes a spontaneous flexible way of relating with the other which wasreplicable away from the residential program. In the following example we begin to see the possibility of reduced prejudice and willingness tolearn from the other:

"You know so in that way it's like we are speaking in a spiritual dimension there's no otherdimension we can speak about so the heart to me is all about that spiritual dimension andI've had this bad habit somehow previously you know where I looked down on people not ina not really looked down but like how could you be this way? But why do you be that wayand I started to realize that I'm looking at my defects in somebody else." (South African male Sahaj Marg practitioner)

This attitude of respect for the other is useful in any consideration of teaching practices based upon notions of bildung. There is also an abandoning of the position where I set myself up as observer and critic of others- i.e. take up a self-located position, which is not centered on self but demonstrates a sense of dispersion. In the following lived example, a practitioner shares her experience of a training program on values,spirituality underpinned by meditative practise and contemplation:

"The first that I can think of is the ISTP experience although there are Abhyasi here beforeI joined the program that bond, that sense of bond is way stronger with the ISTP scholars, perhaps because the spiritual link between us is stronger, we shared the same experiences, and had almost the same goals that made us of oneheart despite thegeographical andcultural divide separating all of us. I met people there who I consider my good friends, whoI can easily open up to. A more macro example will be the good relationship between peopleof differing religions or religious beliefs because they respect each other, despite the fineprint differences of their religions, they remain friends, and consider themselves brothersand sisters. The fact that the basic tenets of their religions are the same help them understandeach other more. Within the Sahaj Marg community, I have met people from differentreligions, or no religions at all, the teachings of Master and the spiritual guidance we have help us become more tolerant, more considerate, more loving, and more respectful of each other." (Phillipino female Sahaj Marg practitioner) 
In this example we see how the experience of the training program creates a sense of connection, tolerance and unity. This may be similar to the concept of bildung is the spiritual formation of integrated, cultivated personalities who would orientthemselves to the Volk community (Trohler, 2003).

\section{Conclusion}

It seems from the applied research with Sahaj Marg Raja yoga practitioners that simple teaching practices including mindfulness, silence and connection may have something to contribute to the development of bildung. Practitioners shared a growth in ways of experiencing the other, which included: reduced prejudice, increased tolerance, flexibility of attitude and capability to learn from the other. It appeared that they began to experience themselves and each other in a rich meaningful way.

Whilst University environments are complex it appears that initiatives are occurring whereby educators introduce ideas of bildung at policy and practice levels. It also appears from the emerging scholarship that students are welcoming of this process.

It seems that thoughts on bildung have had some element of simplistic binary interpretation in that Universities could either be supportive of a market led skills based orientation or a more humanities based exploration and encouragement of personal reflective capacity (Prange, 2004). The lived examples of raja yoga practitioners and case studies fromvarious educational institutions suggests that we can offer the spiritual in an integrated wayor infused way alongside skills training. It is seems to require a values shift and a willingness to move towards aparadigm of wholeness and connectedness. It seems indeed that with such a shift in hospitality anda willingness to offer safe haven within realism; that Universities are ideally located to offer bildung.

\section{References}

[1]. Nordenbo, S. (2002). Bildung and the Tining of Bildung. Journal of Philosophy of Eduction, 36(3): 341 -352

[2]. Bleicher, J. Bildung. Theory, Culture, Society, 23 (2006): 364-365.

[3]. Prange, K. Bildung: a paradigm regained? European Educational Research Journal, 3:(2) (2004):501 - 509

[4]. Reichenbach, R. Beyond Sovereignty: The twofold subversion of Bildung. Educational Philosophy and Theory. 35(2) (2003): 201209.

[5]. Vivekânanda, Swami. Vedânta philosophy: Lectures on Raja Yoga. The Baker and Taylor Company, New York, 1899.

[6]. Prasada, R (Trans). (1912). Patanjalis Yoga Sutras with the commentary of Vyasa and the gloss of Vachespati. MunshiramMancharlal Publishers, New Delhi.

[7]. Prasada, R (Trans). (1912). Patanjalis Yoga Sutras with the commentary of Vyasa and the gloss of Vachespati. MunshiramMancharlal Publishers, New Delhi.

[8]. http://www.upeace.org/

[9]. Pearmain, R. (2005). Transformational experiences in young people: the meaning of safe haven. Int. J. of Children \& Spirituality, 10(3): 277-290.

[10]. Backman, J. Divine and mortal motivation: On the movement of life in Aristotle and Heidegger Continental Philosophy Review, 38 (2006): 241-261.

[11]. Breznitz, S. \& Feldman, M. (2012), The Engaged University, J TechnolTransf, 37:139-157.

[12]. Prasada, R (Trans). (1912). Patanjalis Yoga Sutras with the commentary of Vyasa and the gloss of Vachespati. MunshiramMancharlal Publishers, New Delhi.

[13]. Datur, J. (2005). Universities without "quality" and quality without "universities". On the Horizon, 13(4): 199-215.

[14]. http://www.upeace.org/

[15]. [Pearmain, R. Transformational experiences in young people: the meaning of a safe haven. International Journal of Children's Spirituality, 10, 3 (2005): 277-290.

[16]. Holland, D. Contemplative Education in Unexpected Places: Teaching Mindfulness in Arkansas and Austria. Teachers College Board, 108(9) (2006): 1842-1861.

[17]. Aristotle. The Politics of Aristotle. Trans. Ernest Barker (Oxford, Clarendon Press, Great Britain, 1946)

[18]. Miller, F. (1999). Aristotle's Philosophy of Soul, The review of Metaphysics, 53(2):309-337

[19]. Coholic, D. (2008). Spirituality in Social work pedagogy. Journal of teaching social Work, 26(3/4): $197-217$.

[20]. Sedlmeier, P, Eberth, J, Schwarz, M, Zimmermann, D, Haarig, F, Jaeger, S, and Kunze, S. (2012). The Psychological Effects of Meditation: A Meta-Analysis. Psychological Bulletin 138(6), 1139-71.

[21]. Ho, Li-An. Meditation, Learning, Organizational Innovation and Performance. Industrial Management and Data systems, 111,1 (2011): 113-131.

[22]. Mograbi, G. Meditation and the Brain: Attention, Control and Emotion. Mens Sana Monographs, 9,1 (2011): $276-283$.

[23]. Wang, D., Rao, H., Korozykowski, M., Wintering, N., Pluta, J., Khalsa, D., and Newberg, A. Cerebral blood flow changes associated with different meditation practices and perceived depth of meditation. Psychiatry Research: Neuroimaging, 191, 1 (2011): 60-67.

[24]. Rockefeller, S. Meditation, Social Change, and Undergraduate Education. Teachers College Record,108, 9 (2006): 1775-1786.

[25]. Kaplan, S. Yoga and the Battlefield of Ethics: Highlighting an Infusion Model for Ethics education. Science and Engineering Ethics, 12 (2006): 391-398.

[26]. Hill, C., Herndon, A., \&Karpinska, Z. Contemplative Practices: Educating for Peace and Tolerance. Teachers College Record, 108: 9 (2006): 1915-1935.

[27]. Anderson, V., Levinson, E., Barker, W., Kiewra, K. The Effects of Meditation on Teacher perceived Occupational stress, State and Trait Anxiety and Burnout. School Psychology Quarterly, 14, 1(1999): 3-26.

[28]. Joyce 2012, unpublished PhD

[29]. Trohler, D. The Discourse of German GeisteswissenschaftlichePadagogik- A Contextual reconstruction. PaedagogicaHistorica, 39(6) (2003): 659-778. 